\title{
GCU
}

Glasgow Caledonian

University

University for the Common Good

\section{An optimisation of a freeform lens design for LED street lighting}

Babadi, Sina; Ramirez-Iniguez, Roberto; Boutaleb, Tuleen; Mallick, Tapas

Published in:

2016 International Conference for Students on Applied Engineering, ICSAE 2016

DOI:

10.1109/ICSAE.2016.7810167

Publication date:

2017

Document Version

Author accepted manuscript

Link to publication in ResearchOnline

Citation for published version (Harvard):

Babadi, S, Ramirez-Iniguez, R, Boutaleb, T \& Mallick, T 2017, An optimisation of a freeform lens design for LED street lighting. in 2016 International Conference for Students on Applied Engineering, ICSAE 2016., 7810167, IEEE, pp. 89-92, IEEE International Conference for Students on Applied Engineering (ISCAE), Newcastle, United Kingdom, 20/10/16. https://doi.org/10.1109/ICSAE.2016.7810167

\section{General rights}

Copyright and moral rights for the publications made accessible in the public portal are retained by the authors and/or other copyright owners and it is a condition of accessing publications that users recognise and abide by the legal requirements associated with these rights.

Take down policy

If you believe that this document breaches copyright please view our takedown policy at https://edshare.gcu.ac.uk/id/eprint/5179 for details of how to contact us. 


\section{An optimisation of a freeform lens design for LED street lighting}

\author{
Sina Babadi, \\ Roberto Ramirez-Iniguez \\ and Tuleen Boutaleb \\ School of Engineering and \\ Built Environment \\ Glasgow Caledonian University \\ Glasgow, UK. \\ Email: sina.babadi@gcu.ac.uk
}

\author{
Tapas Malick \\ Environmental and \\ Sustainability Institute \\ University of Exeter \\ Exeter, UK.
}

\begin{abstract}
The number of light emitting diodes (LEDs) used in a variety of applications is increasing rapidly. A good example of an application where this is happening is street lighting. The increasing use of LEDs is due to their advantages compared to other sources of illumination. However, LEDs are not without disadvantages. One of their main drawbacks when used for street lighting without an adequate secondary optic is that they tend to produce a circular footprint with high intensity at the centre and low intensity at the edge of the illuminated area, which prevents them from satisfying national and international standards for uniformity of illumination. This paper presents a new energy mapping method to design a freeform lens to generate uniform illumination of over $95 \%$ on the target plane. The lenses presented in this paper have been designed with two different entrance apertures: (i) A hemisphere subtracted aperture (ii) a flat entrance aperture .
\end{abstract}

\section{INTRODUCTION}

The development of renewable energy technologies and of methods to reduce energy consumption are two ways to solve the environmental problems derived from the use of fossil fuels, which include global warming, air quality deterioration and land pollution [1]. Street lighting is a key public service provided by public authorities at the local and municipal level. Street lighting, for instance, constitutes around $2.3 \%$ of the global electricity consumption in the UK and it costs about $£ 300 \mathrm{~m}$ to power its 7.5 million street lights each year, with prices estimated to increase in the future [2]. Moreover, many street lighting facilities are outdated and therefore highly inefficient. For example there are about 56 million street lights in Europe, of which around 18 million are based on a 1930s standard [3]. In addition, 30\% of light from a standard street light is wasted as it is dispersed upwards [3].

To overcome the environmental problems mentioned above, Light-Emitting Diodes (LEDs) have been used to displace traditional street light sources, which are based on lowpressure sodium (LPS), high pressure sodium (HPS) and high pressure mercury vapour lamps [4]-[6]. The usage of LEDs in illumination systems has become extremely significant due to their unique advantages: high flux efficiency, high reliability, fast response and long life. In addition, they are considered to be environmental friendly by using solid state materials (not using gas or mercury) and because of their low power consumption [7].

Despite enormous advantages of LEDs, it is impossible to implement LEDs directly for the street lighting. Normally, LEDs have Lambertian radiation pattern which illuminates a circle spot on the target plane with high intensity at the centre and low intensity at the edge of the illuminated area [8]. Therefore, it is necessary to combine LEDs with a secondary optic to provide uniform illumination to meet the national and international street lighting standards (e.g. EN 13201 part 1-5 (2013) and BS 5489). A variety of designs for the secondary optics have been proposed and investigated in recent decades [8].

Recently, Mikhail A. Moiseev et al. [9] proposed a method to design an optical element for generating uniform illumination on the large aspect ratio rectangular area. There are multi number internal reflections and refractions at the inside and outside of the optic. This design is based on solving nonlinear differential equations in partial derivatives. The light efficiency of the designed optical element is larger than $83 \%$, whereas the irradiance non-uniformity is less than $9 \%$. However, this design has a complex structure that combines with different light sources with various sizes and light patterns [9].

Non-uniform rational Basis spline (NURBS) and Simultaneously Multiple Surfaces (SMS) are two other methods that have been proposed to design the secondary optics for different applications. The NURBS method is the mathematical model generally used in Computer Graphic and Computer Aided Geometrical Design (CAGD), by offering a rational segmented polynomial curve with flexibility of order of B-Spline [10]. The NURBS method does not work with complex mathematical equations and it offers a common mathematical form to design a standard shape and freeform surface. Yi Ding et al. [11] demonstrated a freeform lens that has been modelled by the NURBS. This optic does not have a smooth surface and it consists of 450 pieces. The length, width and height of the lens 
is $40 \mathrm{~mm}, 36 \mathrm{~mm}$ and $10 \mathrm{~mm}$ respectively and the uniformity across the centre is quite close to $90 \%$ [11].

With regards to the SMS method, two surfaces of lens are constructed at the same time [12]. The design method consists of coupling two pairs of wavefronts that creates two freeform profiles in SMS 2D and surfaces in SMS 3D, that can be either refractive, reflective or a combination of both of them [13]. This method has the ability to produce a lens that maintains uniformity with an extended light source. Oliver Dross et al. [12] have created the RXI LED headlamp design ( which has reflective, refractive and TIR surfaces) without the help of any blocking devices.

This paper proposes a new method to design a single refractive freeform lens to provide uniform illumination on the desired area. A smooth surface lens is generated by changing the emission angles from the light source to the surface. Finally, two different entrance apertures have been examined (i) a hemisphere-subtracted aperture, and (ii) a flat aperture. High-percentage uniformity of over $95 \%$ has been achieved with an extended light source.

\section{THE ENERGY MAPPING BETWEEN THE LIGHT SOURCE AND THE TARGET PLANE}

Figure 1 shows the desired points on the target plane; the desired points are the destination points of the refracted rays towards the target plane. It can be seen in Figure 1, that the desired points on the prescribed area are the intersection points of the rectangular forms and the straight lines. They have been positioned equally from each other on the straight lines.

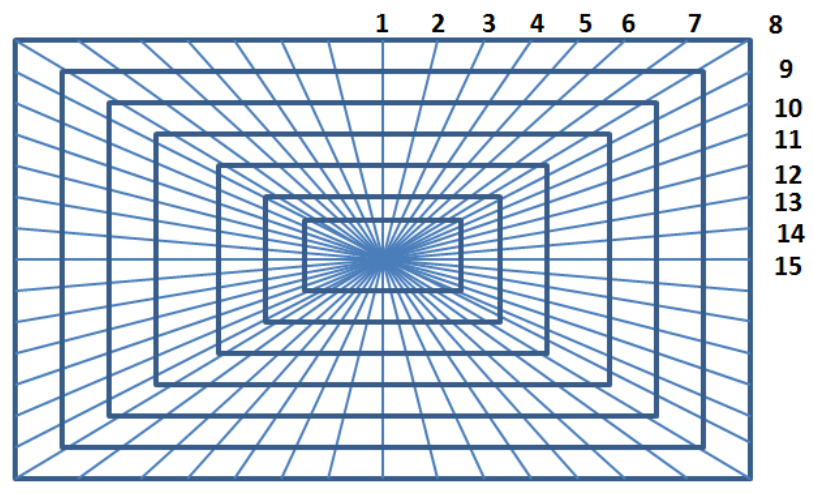

Fig. 1. The rectangular target points mapping based on the rectangular target plane.

These seeds curves have been generated and modified by a semi-automated algorithm to redirect the output rays $\vec{J}$ into the desired points ( $r$ ) on the straight lines. The number of generation of the seed curves depends on the number of the straight lines on the target plane. The surface of the lens is produced by connection these seed curves, therefore the surface of the optic is closer to the desired shape by increasing the number seed curves. Figure 2 shows the output rays have been divided into six emission angles $\left(\theta_{1}\right.$ to $\left.\theta_{6}\right)$, the seed curve distributed these rays toward the desired points. The $\vec{I}, \vec{J}$ and $\vec{N}$ vectors are related via the Snells law shown in Equation 1. $\vec{I}$ is the ray from the light source toward the seed curve, $\vec{J}$ is the light ray refracted from the seed curve to the desired point on the target plane and $\vec{N}$ is the Normal vector that stands on the seed curve. In Equation 1, $\vec{n}_{i}$ and $\vec{n}_{j}$ are refractive indices of the media inside and outside of the lens respectively.

$$
n_{j} \times \vec{J}-n_{i} \times \vec{I}=\left[n_{j}^{2}+n_{i}^{2}-n_{j} \times n_{i}(J \times I)\right]^{0.5} \times N
$$

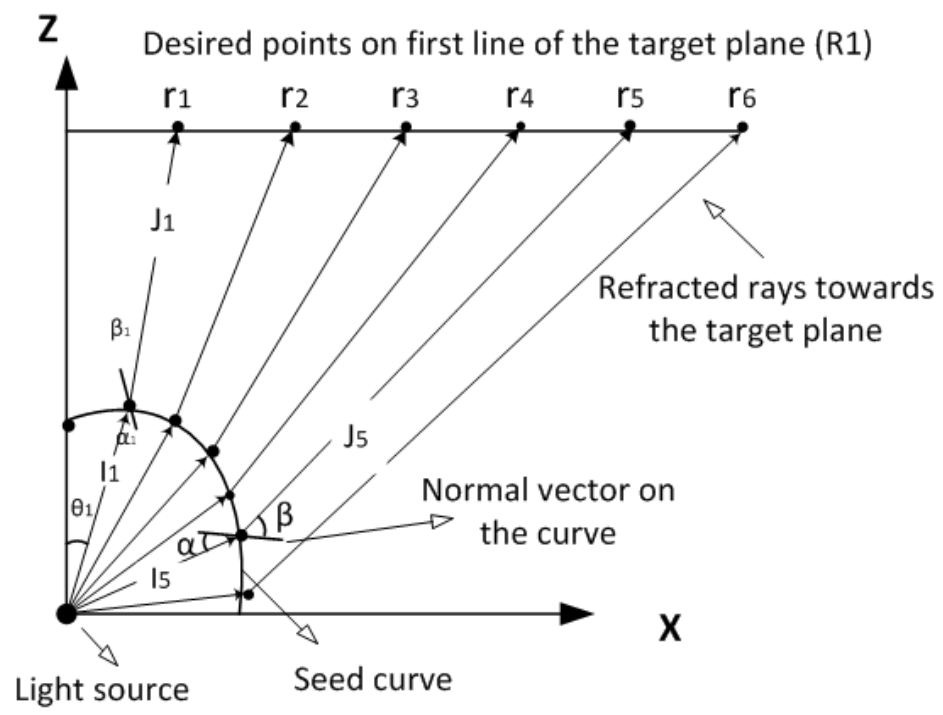

Fig. 2. The ray tracing at the inside and the outside of the optic.

The size of the seed curve is related to the size of the length of the straight line and the emission angles of incident and refracted rays. The difference between the length of the line 1 (the smallest line) and line 8 (the longest line) effects on the surface of the lens and its footprints. To have a smooth surface of the lens, it is necessary to make the length of these seed curves more equal . Figure 3 (a) shows the size of the emitted angles increased from $\theta_{1}$ to $\theta_{6}$, therefore the seed curve of the straight line 1 become larger than the original curves (the dash line). And also Figure 3 (b) shows the new seed curve of the straight line 8 is smaller than the original one (the dash line) by reducing the size the emission angle from $\theta_{1}$ to $\theta_{6}$.

The entrance aperture of the optic can be a (i) a hemisphere subtracted or (ii) flat. Figure 4 (a) shows an extended light source placed at the centre of the hemisphere subtracted aperture; the rays enter the optic with minimum the refraction. However, Figure 4 (b) shows the same light source placed at the centre of the flat entrance aperture. There is less than 0.5 $\mathrm{mm}$ gap between the light source and the optic in Figure 4 (b). Both lenses have been designed based on the same energy mapping as shown in Figure 1. However, it is clear from Figure 4 that there is a difference between the surfaces of both lenses due to different structures of the entrance apertures. Figure 4 

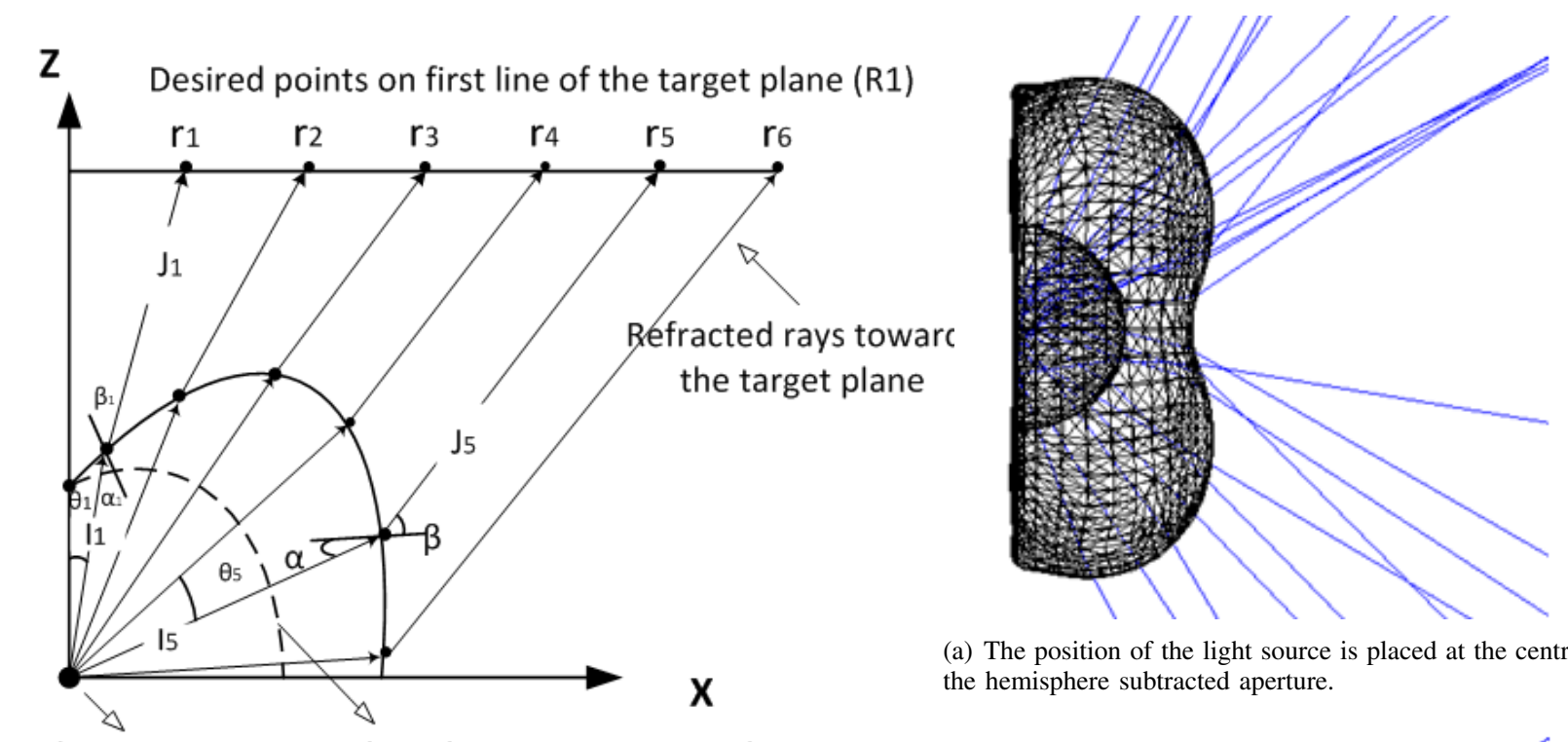

(a) The position of the light source is placed at the centre of the hemisphere subtracted aperture.

\section{Light source Original seed curve New seed curve}

(a) The new larger seed curve of the straight line 1 .

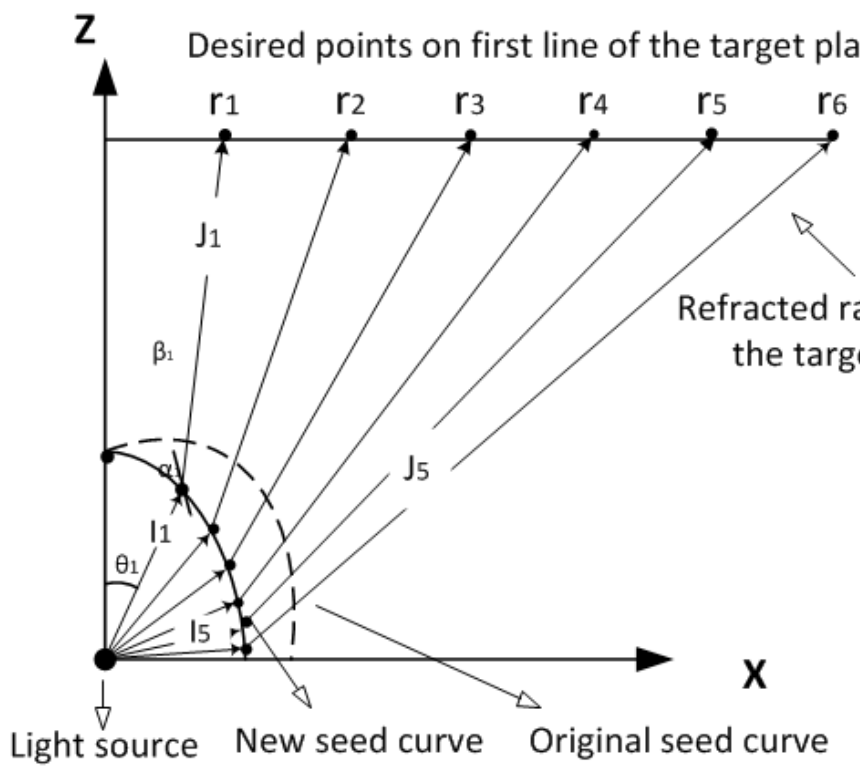

(b) The new smaller seed curve of the straight line 8 .

Fig. 3. Changing the size of the seed curve by changing emission angles.

shows random rays from the tracing simulation at the cross section of the inside and the outside of the lenses.

The two advantages of the hemisphere subtracted aperture are:

- This gap reduces the effects of the temperature of the LED on the optic.

- It decreases the volume of the lens therefore it impacts on the cost and weight of the optic.
(R1)

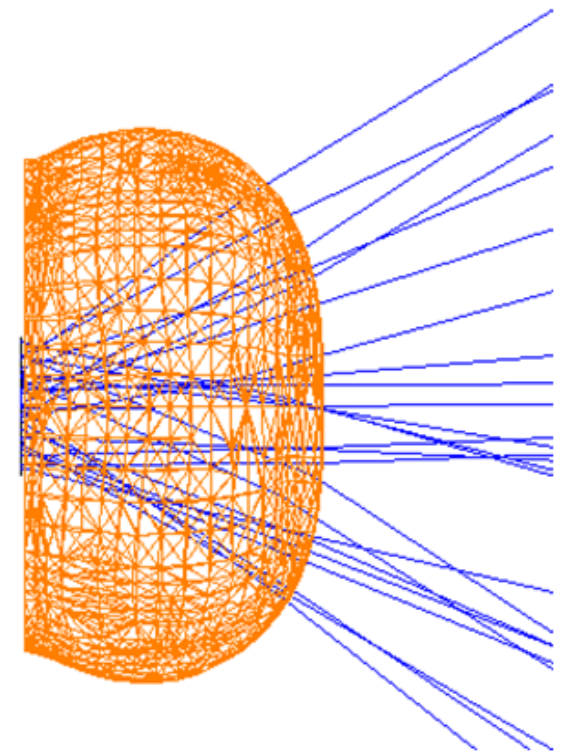

(b) The position of the light source is placed at the centre of the flat aperture

Fig. 4. The ray tracing at the inside and outside of the optic

\section{THE ZEMAX SIMULATION RESULTS}

In order to use this lens for the street lighting illumination, a high power LED has been chosen to provide adequate light intensity at the target plane. In the ray tracing simulation process, the data sheet of a Cree lamp CXA 1507 has been used. This LED has an emission area of $8.9 \mathrm{~mm}$ in diameter with a lambertian radiation pattern.

Figure 5 shows the uniformity of over $95 \%$ on the target plane that correspond to the flat entrance aperture design combined with the above LED. It is placed at a 6 meters distance to provide uniformity at the target plane. A rectangular illuminated area is generated with a length of 7 meters and a width of 3 meters. 


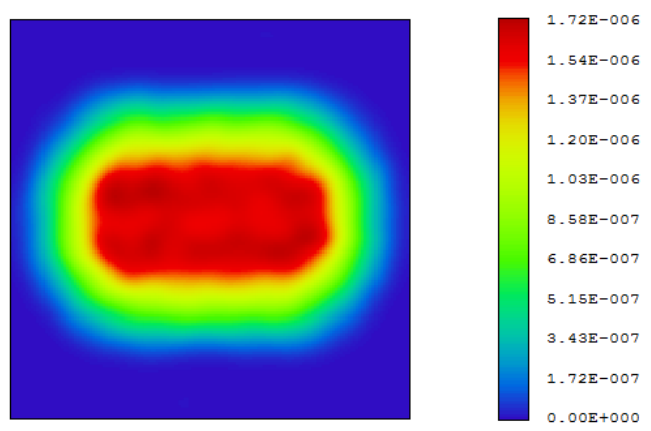

(a) Irradiance distribution on the target plane.

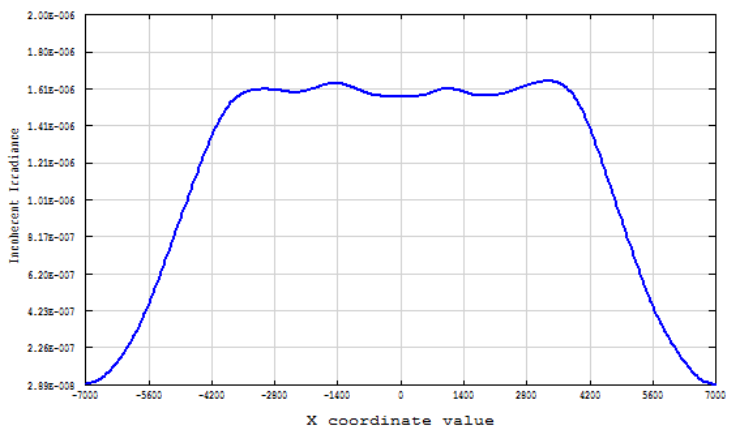

(b) The cross section of the light distribution on the $\mathrm{X}$-axis.

Fig. 5. The footprint of the flat entrance aperture lens.

\section{CONCLUSION}

In this research, a new design method has been proposed to generate a smooth surface lens to provide uniform illumination within a rectangular area. This method introduces a new energy mapping technique to redirect light from the light source to the target plane with simple mathematical equations. This energy mapping generates the seed curves, and the smooth surfaces of the lenses are generated by connecting these curves. The LEDs are combined with the lenses with the hemisphere subtracted and the flat entrance aperture. Both lenses have been examined as in a ray tracing software called ZEMAX with the factory data of the Cree lamp CXA 1507. Over $95 \%$ uniformity has been achieved with minimum transition between the illuminated area and the dark area.

\section{ACKNOWLEDGMENT}

The authors would like to thank the Energy Technology Partnership (ETP), Optical Antenna Solution (OAS) and Glasgow Caledonian University for their funding to conduct this research .

\section{REFERENCES}

[1] S. Babadi, R. Ramirez-Iniguez, T. Boutaleb, and T. Mallick, Performance analysis of a DTIRC-led illumination structure, in Optics and Measurement Conference 2014, (International Society for Optics and Photonics, 2015), pp. 944205.

[2] BBC News UK. "Fears over street light cut-backs". http://www.bbc.co.uk/news/ uk-11209143, September June 2010.

[3] European PPP Expertise Centre, "Guidance on Energy Efficiency" http://www.eib.org/epec/resources.pdf.
[4] A. Haans and Y. A. de Kort, Light distribution in dynamic street lighting: Two experimental studies on its effects on perceived safety, prospect, concealment, and escape, Journal of Environmental Psychology 32, 342352 (2012).

[5] S. M. Ghoreyshi, A. Shahrabi, and T. Boutaleb, An inherently void avoidance routing protocol for underwater sensor networks, in 2015 International Symposium on Wireless Communication Systems (ISWCS), (IEEE, 2015), pp. 361365.

[6] M. A. Fard, A. Akbari, R. Shojaee, H. R. Mirzaei, and P. Naderi, Partial discharge defects classification using neuro-fuzzy inference system, in 2010 10th IEEE International Conference on Solid Dielectrics, (IEEE, 2010), pp. 1-4.

[7] S. Babadi, R. Ramirez-Iniguez, T. Boutaleb, and T. Mallick, Analysis of uniformity of illumination of a freeform lens when combined with different optical sources, in SPIE OPTO, (International Society for Optics and Photonics, 2016), pp. 974417.

[8] S. Babadi, R. Ramirez-Iniguez, T. Boutaleb, and T. Mallick, Novel nonimaging optic design for uniform illumination, in SPIE OPTO, (International Society for Optics and Photonics, 2016), pp. 976416.

[9] M. A. Moiseev, L. L. Doskolovich, and N. L. Kazanskiy, Design of high-efficient freeform led lens for illumination of elongated rectangular regions, Optics express 19, A225A233 (2011).

[10] C. Brecher, S. Lange, M. Merz, F. Niehaus, and M. Winterschladen, Off-axis machining of nurbs freeform surfaces by fast tool servo systems, Proceedings of the M 4, 2006, (2006).

[11] Y. Ding, X. Liu, Z.-r. Zheng, and P.-f. Gu, Freeform led lens for uniform illumination, Optics Express 16, 1295812966 (2008).

[12] O. Dross, R. Mohedano, P. Benitez, J. C. Minano, J. Chaves, J. Blen, M. Hernndez, and F. Muoz, Review of sms design methods and realworld applications, in Optical Science and Technology, the SPIE 49th Annual Meeting, (International Society for Optics and Photonics, 2004), pp. 35-47.

[13] R. Wu, Z. Zheng, H. Li, and X. Liu, Optimization design of irradiance array for led uniform rectangular illumination, Applied optics 51, 2257 2263 (2012). 